This is a post-print version of an article published in:

Webber, G. et al. (2010). Life in the big city: The multiple vulnerabilities of migrant Cambodian garment factory workers to HIV. Women's Studies International Forum, 33(3), 159-169.

doi: 10.1016/j.wsif.2009.12.008.

\title{
Life in the Big City: \\ The Multiple Vulnerabilities of Migrant Cambodian Garment Factory Workers to HIV
}

Gail Webber

Department of Family Medicine, University of Ottawa, Canada

Nancy Edwards

School of Nursing and Department of Epidemiology and Community Medicine, University of Ottawa, Canada

Ian D. Graham

Canadian Institutes of Health Research, Ottawa, Canada

Carol Amaratunga

Justice Institute, British Columbia, Canada

Vincent Keane

Formerly of International Organization for Migration, Cambodia

Ros Socheat

International Organization for Migration, Cambodia

Correspondence: Dr. Gail Webber, Lancaster Medical Clinic, 2450 Lancaster Road, Units 11 and 12, Ottawa, ON, Canada, K1B 5N3

Tel: (613) 738-9119 or (613) 233-3101

Fax: (613) 738-2736

Email: gwebb035@uottawa.ca

Shortened Title: Life in the Big City ${ }^{1}$

\footnotetext{
${ }^{1}$ Acknowledgements: The authors would like to acknowledge the support and assistance of the following organizations in this research: International Organization for Migration, Cambodia, CARE Cambodia, and the Reproductive Health Association of Cambodia. The two Cambodian research assistants Mora Gibbings and Phoumy Ouch provided invaluable help, Dr. Lynne Leonard made helpful conceptual comments, and Dr. Alison Hamilton's guidance on qualitative analysis was also appreciated. Finally, we wish to thank our key informants, our focus groups participants, and particularly the garment workers who took the time to meet with us and share their stories. Financial support for the study was provided for the first author through the Ontario Women's Health Council Scholar's Doctoral Award, and from the Department of Family Medicine, University of Ottawa.
} 


\begin{abstract}
:
Cambodia has one of the highest prevalence rates of HIV in Asia; an increasing number of HIV positive Cambodians are women. The purpose of this qualitative study was to assess the context of HIV prevention for rural-to-urban migrant Cambodian female garment factory workers. Interviews with migrant garment factory workers and key informants, and focus group with health care providers confirmed that poverty was the primary motivator for migration. Women and key informants reported awareness that some migrants had sexual relationships with local men or engaged in sex work to supplement their income. Factory restrictions limited women's ability to access health care services and health education programs. Key themes of the research were economic, social and occupational vulnerabilities of these migrant workers placed them in a context of increased risk of acquiring HIV. Interventions to reduce the risk of HIV infection for migrant Cambodian garment factory workers should address these themes.
\end{abstract}




\section{BIOGRAPHICAL STATEMENT:}

Dr. Gail Webber is an assistant professor of Family Medicine at the University of Ottawa and she has a community family medicine practice. She received a Ph.D. in Population Health at the University of Ottawa, based on this research on the vulnerability of migrant Cambodian garment factory workers to HIV. Her research interests include women's health issues and HIV prevention.

Dr. Nancy Edwards is a professor in the School of Nursing and Department of Epidemiology and Community Medicine, at the University of Ottawa. She holds a Nursing Chair funded by the Canadian Health Services Research Foundation, the Canadian Institutes of Health Research and the Government of Ontario. The focus of her research is multi-strategy and multi-level interventions in community health. She is also the Scientific Director of the Institute of Population and Public Health, Canadian Institutes of Health Research.

Dr. Ian Graham is Vice President for Knowledge Translation at the Canadian Institutes of Health Research, Ottawa and Associate Professor, School of Nursing, Faculty of Health Sciences and Department of Epidemiology and Community Medicine, Faculty of Medicine, University of Ottawa.

Dr. Carol Amaratunga currently serves as the Dean, Applied Research, Justice Institute of British Columbia. Carol is the former Ontario Women's Health Council Chair, University of Ottawa and Principal Investigator of the Atlantic Centre of Excellence for Women's Health, Dalhousie University. She believes in applied research that inspires social change and social justice.

Dr. Vincent Keane is a public health physician with twenty five years experience in international health and is the Former Chief of Mission at the International Organization for Migration, Cambodia. His specific interests include emergency response management, health issues of refugees and displaced persons and tuberculosis program development and management.

Dr. Ros Socheat is a Cambodian physician trained in Vietnam with a special interest in the health of migrants and displaced persons, as well as humanitarian work. Dr. Socheat is presently working with the International Organization for Migration in Cambodia and has been involved in the medical processing of refugees, migrants and the demobilization of soldiers in the Royal Cambodian military. 


\section{Life in the Big City: \\ The Multiple Vulnerabilities of Migrant Cambodian \\ Garment Factory Workers to HIV}

\section{Context of Migration and the HIV Epidemic in Cambodia}

Migration often increases vulnerability to HIV infection (Decosas, Kane, Anarfi, Sodji, \& Wagner, 1995; MacPherson, Gushulak, \& Macdonald, 2007; Quinn, 1994). This phenomenon has been well described for populations of women migrants in a diversity of situations (Webber, 2007), and for rural-to-urban migrants of both genders in China (Hong et al., 2006; Hu, Liu, Li, Stanton, \& Chen, 2006; Yang, Derlega, \& Luo, 2007). Internal migration in Cambodia is a common phenomenon (Maltoni, 2006), and poverty is the main impetus for rural-to-urban migration in Cambodia (Nareoun, 2004). Close to 300,000 workers are employed in the garment factories of Cambodia's capital, Phnom Penh, and the vast majority of these garment factory workers are rural-to-urban migrant women aged 18 to 25 years old (CARE Cambodia, 2006; International Labour Organization, 2005).

Cambodia has one of the highest prevalence rates of HIV in Asia, with a peak adult prevalence of $3.9 \%$ in 1999 (United Nations Development Program, 2007), levelling at $0.9 \%$ in 2006 (UNAIDS, 2007a). HIV first became evident in the Cambodian blood system in 1991, after the Cambodian infrastructure had been decimated by years of civil war. In the subsequent decade, thousands of Cambodians became infected. Currently, about 130,000 people live with HIV in this country of 14 million, although only a minority are aware of it (UNAIDS, 2007b). In recent years, an increasing proportion of HIV positive Cambodians have been women. Experts on the Cambodian HIV epidemic have highlighted the need for research and HIV prevention amongst vulnerable groups as the virus moves from high risk groups into the general population (Saphonn et al., 2004). The purpose of this study is to understand the multiple contextual factors 
of migrant garment factory workers' lives which put them at risk of HIV infection. This understanding is key to future program development and effective policies directed towards HIV prevention for this population of women.

It has been well documented that the context of women's lives has an enormous impact on their vulnerability to HIV (Doyal, 1994; de Bruyn, 1992; Gupta \& Weiss, 1993; Heise \& Elias, 1995; Schoepf, 1992; Zierler \& Krieger, 1997). Historically, however, approaches to sexual and HIV research which have relied on surveys and focussed on behavioural risks have been inadequate to explore the wider social, cultural, economic and political factors which can shape sexual experiences and HIV risk (Parker \& Aggleton, 2007). Thus, the socio-ecologic model of HIV prevention (Webber, 2007) was used as the guiding theoretical framework for this research. The socio-ecologic context of HIV has been described for the geo-political contexts of Eastern Europe (Rhodes \& Simic, 2005) and southern Africa (Beyrer, 2007). These authors have noted that the socio-ecologic context (also referred to as the risk context) consists of multiple, often interacting layers stretching from individual behavioural risks, to relationship dynamics, community factors, and structural impacts at the policy level. This framework was chosen for the research as it provides a structure with which to explore the multiple factors impacting on HIV prevention for migrant women. Figure 1 illustrates how the socio-ecologic context of HIV prevention for migrant women shifts from their community of origin to their destination. In particular, shifts in the power dynamics of sexual and non-sexual relationships, community factors (such as access to health care resources, labour opportunities, and risk behaviour profiles), and the structural context of the destination (including cultural norms, stigma and policies as they apply to migrants) may all potentially impact on HIV prevention for these 
migrant women. It is the purpose of this study to elucidate which factors of this socio-ecologic framework are important for these migrant Cambodian garment factory workers [Figure 1]

\section{Literature Review}

Given the focus of the study, we reviewed the literature in three specific areas: gender norms in Cambodia, Cambodian literature on migrant women, and the international literature on migrant women and HIV.

\section{Gender Norms in Cambodia}

A fundamental key to understanding the vulnerability of migrant Cambodian women to HIV is a clear perception of gender norms and relations in this country. Several authors have made important contributions to a greater understanding of the context of gender relations in Cambodia. In her review of Cambodian gender ideals, Derks (2008) discussed both Ebihara and Ledgerwood's work in this area. In her pre-civil war research amongst village women, Ebihara (1974) determined that one of the key responsibilities of young women was the protection of their virginity. Indeed, Ledgerwood (1990) confirmed that the whole family's reputation was dependent upon the maintenance of virginity in the daughter. Derks (2008) documented that the historical gender ideals continue to be taught to young women today. Restrictions on sexual activity do not apply to young Cambodian men however. Interviews with Cambodian youth (Tarr \& Aggleton, 1999) and university students in Phnom Penh (Glaziou et al, 1999) demonstrated that Cambodian men enjoy much more sexual freedom than women. Many urban and rural young men have routine liaisons with a variety of partners, including sex workers, while women 
are much less sexually active. Tarr and Aggleton (1999: 376) summarized the emphasis on chastity for young women:

...virginity is a commoditized symbol [for women]. It still means much to most Cambodians, young or old, and the whole society has a 'stake' in the virginity of young women.

The gendered nature of sexual behaviour combined with the poverty of many Cambodian families, fuels a very strong commercial sex industry in the country (Mills, Singh, Orbinski, \& Burrows, 2005). Despite the gender norms of their society, some poor rural women use sex work as a means to support themselves and their extended families (Sandy, 2006). Indeed, most of the research on Cambodian rural-to-urban migrants has been conducted with direct and indirect sex workers (Gorbach et al., 2005; Kim et al., 2006; Ohshige et al., 2000a; Ohshige et al., 2000b; Prybylski \& Alto, 1999; Wong et al., 2003). These studies of migrant sex workers illustrate the vulnerability of migrant women to HIV, as in the past condoms have not been routinely used in their sexual encounters with male clients or with their regular partners (Kim et al., 2005; Prybylski et al., 1999; Wong et al., 2003). Through the influence of prevention programs, particularly Cambodia's $100 \%$ condom policy for brothels, recent quantitative evidence suggests that condom use for sex workers is increasing, although more with clients (transactional sex) than "sweetheart" partners (Gorbach et al., 2006). Thus, the gender norms of Cambodian society are an important part of the socio-ecologic context affecting HIV prevention for women.

\section{Cambodian Literature on Migrant Women}


There is very little published literature on HIV and Cambodian rural-to-urban migrant garment factory workers. In a wide search of multiple databases (CINAHL, Embase, Medline, Psychinfo, Genderwatch, Women's Studies International, eHRAF Collection of Ethnography and Sociologic Abstracts) using the key words "Cambodia", "migration", and "HIV", only a single study on garment factory workers was found (Nishigaya, 2002). Beyond this, there are a limited number of studies published elsewhere and in the grey literature. The paucity of research on this population is strong rationale for the importance of this research.

Nishigaya (2002) described the findings of interviews with twenty garment factory workers who supplemented their income by work in the sex trade. She explored the women's reasons for engaging in sex work, their working conditions in the sex industry, their "sweetheart" relationships, and their partners' use of condoms. She concluded that it is the context of poverty that forces these migrant women to find ways to support themselves and their families outside their work in the factories, and that this work is highly risky to them as condoms are not always used. Nishigaya's work is important for its focus on a unique population in the published literature, and for determination of the vulnerability to HIV of some garment factory workers through their work in the sex trade industry.

CARE Cambodia $^{2}$ has reported on the reproductive health of migrant garment factory workers, as this non-governmental organization has developed health education programs for these workers (CARE International in Cambodia, 1999). Most of the respondents sought employment in the garment factories of Phnom Penh because of poverty and a lack of opportunities in their home provinces. While they reported long working hours and insufficient income through their work in the factory, the garment factory workers had relatively good

${ }^{2}$ CARE Cambodia is part of CARE International. This non-governmental organization works to alleviate poverty in Cambodia. One of the focuses of CARE's work in Cambodia is HIV education to women at risk, including garment factory workers. 
knowledge about the sexual transmission of HIV in both this study (CARE International in Cambodia, 1999) and in a later CARE study (CARE Cambodia, 2003).

The Cambodian National Center for HIV/AIDS, Dermatology and STDs also produced a report on sexual risks of HIV in garment factory workers (National Center for HIV/AIDS Dermatology and STDs \& University of California, 2005). This quantitative study included a survey to assess sexual activity and biomarker testing for HIV and Herpes Simplex virus type 2. The authors determined that the rates of risk behaviour and prevalence of the Herpes Simplex type 2 (HSV) and HIV viruses were low. Only 2 women tested positive for HIV initially, and another woman acquired it during the study (incidence $0.3 \%$ ), while 11 women acquired HSV during the study (incidence 2.1\%). There were 13 women (3.8\%) who stated they never had sex, but were HSV positive (p. 26). The authors concluded that garment factory workers are not highly sexually active outside of marriage and should not be considered a high risk group for HIV.

These few reports on migrant Cambodian garment factory workers have several limitations. Nishigaya's (2002) conclusions from her qualitative research on garment factory workers who supplemented their income with sex work have relevance to other populations of migrant workers, as poverty and vulnerable employment situations are commonplace. However, her focus was exclusively on a subset of women who worked in the sex trade. Her study of garment factory workers may not apply to those garment factory workers who do not engage in transactional sex. Thus this research, including garment factory workers who are not involved in the sex trade, is warranted.

Similarly, caution is required in interpreting the Cambodian National Center for HIV/AIDS, Dermatology and STDs' survey data about the limited sexual activity of garment factory 
workers. Quantitative methods may result in under-reporting of sexual activity, depending on the specific wording of the questions. In addition, Herpes Simplex virus type 2 is an imperfect proxy for sexual activity as the prevalence of this virus in the Cambodian population is not known. Finally, even if this study were correct in stating that there is a limited percentage of garment factory workers who are at risk of HIV through sexual activity, with a population of garment factory workers in Phnom Penh alone approaching 300,000, this still equates to thousands of women vulnerable to infection. The most significant limitation of this survey, however, is the predominant focus on the individual's sexual risks of acquiring HIV, rather than the broader socio-economic context that produces this vulnerability. A brief review of some of the international studies on migrants is warranted to elicit a wider perspective of the factors impacting on HIV prevention for migrant women.

\section{International Literature on Migrant Women and HIV}

A review of the international literature (Webber, 2007) has demonstrated that women who have migrated within their country or across international borders are particularly vulnerable to HIV as a result of limited access to health care, the change in norms and social supports in their new environments, and, as was found by Nishigaya (2002), lack of sufficient income that results in the economic need for generating income through sex work. Health care access provides opportunities for education about safer sexual relations, access to condoms, and early diagnosis and treatment of sexually transmitted infections that may contribute to HIV vulnerability. Limited access to health care has been a problem for Hispanic farm workers in Florida as over 90\% lack health insurance (Fernandez et al., 2004). Hong Kong migrant domestic workers also 
experienced health care access issues as they described episodes of discrimination and breaches of confidentiality at Hong Kong hospitals (Bandyopadhyay \& Thomas, 2002).

Three studies of Chinese migrants have demonstrated how the change of norms and social supports in the migration destinations increased the vulnerability to HIV for women migrants (Hong et al., 2006; Yang \& Xia, 2006; Yang et al., 2007). There are a number of other examples of migrant women from diverse regions of the world who used commercial sex work to supplement their income thereby increasing their vulnerability. Migrant women working on sugar cane plantations of the Dominican Republic (Brewer et al., 1998), Hispanic farm workers in the United States (Fernandez et al., 2004; Gadon, Chierici, \& Rios, 2001), and Burmese factory workers in Thailand (Mullany, Maung, \& Beyrer, 2003) have all relied on sex work as an income supplement and consequently this has been termed an "interim survival strategy" for migrant women (Brewer et al., 1998).

Thus, a variety of factors increase migrant women's vulnerability to HIV. Although these studies used different methods, they all relied on data from the migrants themselves about their experience of migration. However, a "key informant" perspective was not evident in the literature. To explore the broader socio-ecologic framework of HIV prevention, input from the migrants benefits from supplementation by key informants who have knowledge of the migrants' experiences and can comment on the individual, community and structural factors that may have an impact on HIV prevention for these migrants.

\section{Methods}

To determine the socio-ecologic contextual factors affecting HIV prevention for these migrant workers, we conducted a qualitative study of female rural-to-urban migrant garment factory 
workers in Phnom Penh Cambodia in 2006.The study was the first phase of a larger mixed methods research project (Webber, 2008). The methodology of the study reported in this paper was ethnographic. Phnom Penh is the capital of Cambodia and the largest city in the country, containing about two million of Cambodia's fourteen million residents, and home to thousands of rural-to-urban migrant garment factory workers.

Prior to embarking on this research project, a formal agreement was established between the University of Ottawa and the International Organization for Migration Cambodia, for the purposes of research collaboration. Ethical approval for the study was obtained from both the Cambodian National Ethics Committee and the University of Ottawa Research Ethics Board. The data collection procedures involved semi-structured interviews with the migrant garment factory workers and key informants, and focus groups with health care providers. With the approval of both ethics committees, each participating migrant woman, and health care providers in the focus groups were paid US\$3.00 in recognition of their time. The migrant women were also given a small stipend (US\$0.50) for travel if they required local transportation to get to the interview. The key informants were not paid. The perspectives of both migrant women and key informants were sought to address a broad range of issues on the vulnerability of migrant women to HIV, from multiple points of view.

All interviews were conducted by the first author and two female Khmer research assistants. The female gender of the interviewers was an important factor as some of the research questions involved issues of sexual intimacy and Cambodian women would find such discussions with a male inappropriate. Interviews with the garment factory workers were conducted late in the day or on a Sunday in a private home close to the factories so as not to interrupt the research participants' work schedule. These strategies of ethnically and gender matched interviewers and 
attention to the timing and circumstances of the interview were adopted for researching sensitive topics in ethnically diverse populations (Elam \& Fenton, 2003).

The inclusion criteria for the migrant women were rural-to-urban migration within the last 10 years, and age of at least 18 years. The migrant garment workers were recruited using a purposive sampling approach, in order to have women of differing marital status and health care experiences represented (maximum variation sampling). All of the interviews were conducted in Khmer by a research assistant, with simultaneous whisper translation to English for the first author by a second research assistant. Simultaneous translation facilitated effective interviewing as the researcher was able to respond to the research participants immediately for clarification or further probing. The migrant garment workers were indirectly asked about their contextual issues for HIV prevention through enquiry of their migration experiences. Many of the young migrants were shy, and prompting was often required to elicit their response to sensitive questions such as their knowledge and experience of sexually transmitted infections and HIV.

Key informants in Phnom Penh who worked with garment factory workers were also recruited for interviews. These key informants were recruited through convenience sampling, with deliberate inclusion of individuals from both government and non-governmental organizations. The interviews were conducted in the workplace of the informant, in English or Khmer. Key informants were asked directly about individual, community, and structural factors that impact on HIV prevention for migrant garment factory workers. The role of key informants in educating the researcher and enriching the data has been well described (Gilchrist, 1992). Key informants were important contributors to this study as they were able to raise issues that the garment factory workers were not aware of, such as the organization of health education 
programming and the impact of government policy on HIV prevention. Saturation was reached on many of the topics discussed by the migrants and key informants.

Finally, two focus groups were held with health care providers working in Phnom Penh clinics that served garment factory workers' reproductive health care needs. The focus groups were conducted in Khmer with simultaneous translation to English and the discussion addressed the most important issues that prevent migrant garment factory workers from protecting themselves from HIV.

Translated interviews were transcribed and were checked for accuracy by one of the Khmer research assistants. Analysis of the data was assisted by the use of the qualitative software program Atlas-ti. Transcripts were organized into document families based on the demographic differences in the research participants. Data were then analyzed through an iterative process of multiple readings of the text noting recurrent ideas, coding for common concepts, and constructing matrices of related themes. This constant comparative method led to a determination of emerging and recurrent themes in addition to a priori categories. The themes of the research were organized into levels as found in the socio-ecologic model: relationship issues, community factors and larger structural issues.

\section{Limitations}

This research has several potential limitations related to either the study design or the study findings.

Study Design Limitations 
Time was a significant limitation of the research, as the workers had very little free time, and only spent about 60 to 90 minutes with the research team (including the time required for translation). Opportunities to interview women on more than one occasion, and before and after their migration to the city would probably have allowed the women to become more comfortable with the research team and may have encouraged them to share more information about themselves, providing richer data. Time limitations were also an issue for the key informants and health care providers, as these participants had other responsibilities to return to.

Cultural differences between the researchers and the research participants were another concern. The perspective of the Canadian researcher as both a physician and feminist from a Western culture may have affected data collection and interpretation. To mitigate these cultural differences, two Khmer female research assistants were employed to assist with interviewing. Despite ethnicity and gender matching of research assistants, there remained a gap in socioeconomic status between the research assistants and the research participants, a noted limitation of cross-cultural research (Temple, 2002). The research assistants were consultants with considerable experience working with government and non-governmental organizations, were older than the research participants, and were based in Phnom Penh providing them with a different world view and status from the research participants who all originated from the country-side (Derks, 2008). However, both research assistants had experience interviewing rural Cambodians of lower socio-economic status, thus minimizing the impact of this limitation.

Another study design limitation was the exclusion of the male partners' views on this topic. The perspective of male partners' would have made an interesting addition to the study in order to understand the sexual relationship power dynamics and cultural gender norms experienced by 
these migrant women. As the vulnerability of the garment factory workers to HIV is mainly through sexual risks, male partners are key actors in this process.

\section{Limitations of Findings}

Under-reporting and response biases may occur for a variety of reasons in sexuality and HIV research (Wiederman, 2002). In this research, lack of memory or recall about the item, degree of insight into the issue, and social desirability response bias may have all been limiting factors. In particular, social desirability response bias was likely an issue, especially for the single women research participants, because of the stigma against premarital sex and women's sexual knowledge in this society. However, this social desirability bias is prevalent in all sexual health research, and thus not unique to this study (Stone, Catania \& Binson, 1999).

This research has several other potential limitations. Our sample of 20 migrant garment factory workers was small, and from one area of Phnom Penh only. However, our participants were similar ages to the majority of garment factory workers (18 of the 20 migrants were under 30 years old, as is common of garment factory workers) (International Labour Organization, 2005); maximum variation sampling ensured that diverse experiences were represented in the group. The minimal diversity of key informants was another limitation; representation from factory management, and senior government officials would have augmented our understanding of other structural factors such as the implications of global trade policies for these women. Despite these limitations, we attempted to ensure the trustworthiness of the findings through maximum variation sampling of the migrant women, including women with different sexual and health care experiences, and by including the views of the key informants. 


\section{Results}

Twenty migrant garment workers and eight key informants were recruited and interviewed. The key informants worked in government positions (three) and local NGOs (five). Two focus groups were held with a total of 13 health care providers.

\section{Demographic Description of the Migrant Women}

The average age of the interviewed women was 24.5 years (range age 18 to 39). Most of the migrant women (18 of the 20) were under the age of 30 . The women had all migrated within the last 10 years; 13 of the 20 had migrated within five years. All of the women described themselves as Khmer (Cambodian). They had all migrated from provinces in the south-east of the country, surrounding Phnom Penh. Twelve of the 20 women were single, including two engaged women, and one with a boyfriend. Six of the migrants were married, one was widowed and one was divorced.

Most had less than nine years of schooling; all were fluent in the Khmer language, and a few had some knowledge of a second language. Of the 17 women who read Khmer, over half described their ability as limited. Two women were illiterate. Almost all of the migrant women had previously worked as farmers, usually cultivating rice. The research participants had a variety of roles in the process of garment production, including cloth organizer or counter, marker or cutter of the cloth, tailor, seam finisher, ironer and packer of the finished product.

\section{Experience of Life in the Big City for Migrant Garment Factory Workers}


Almost universally, the women interviewed migrated to Phnom Penh for the primary purpose of financially supporting their families, as they all were living in subsistence poverty in their villages. Most of the women made the decision to migrate themselves, although several were encouraged to pursue factory jobs by their families. The experience of the migrant quoted below illustrates the challenges many of these young women faced at home:

The idea to come here was from me. My family was in difficult circumstances. My father was sick, and my mother is very old, and my family is poor, with very difficult living conditions. So I came with my cousin to the city. I was happy to come here as I could get money to support the family. The reason to come to the city is for financial problems, and also I want to earn money to keep for my future. (Migrant Woman 7 , single, age 22, migrated 4 years ago)

Migration from the countryside was an enormous change for these young women: several women lamented the loss of opportunity to complete their education, as their commitment to their family's economic needs took them into the workforce prematurely. Their work in the garment factory impeded their ability to continue to improve themselves. When asked what other comments she had about moving to the city, this young woman replied:

I would like to suggest that we need opportunities to learn to read and write. When I arrived here, I could not read. I would like a program to improve the factory girls reading, writing and maybe even speaking in English. (Migrant Woman 7, single, age 22 , migrated 4 years ago)

In addition to missing their lost opportunities for education, several of the migrant women recalled the loneliness and fear they experienced after migration. They worried about being cheated, and missed the closeness of their families and community. Several of the migrants described concerns for their safety, particularly when they saw groups of young men congregating on the streets.

I am afraid of the boys when they get drunk, when people fight on the street. This makes me afraid. I prefer the village. I am only in Phnom Penh for the money. I have heard about a case of rape, but this has never happened to me. I am afraid of this. (Migrant Woman 2, single, age 25, migrated 5 years ago) 
While several of the women were distressed by their move to the city, the income they generated through their work in the factories was welcome. The garment factory workers interviewed related that they usually earned US\$45-55 per month for regular working hours (an 8-hour day, six days per week); however, many worked overtime hours into the evenings or weekends to earn extra money. These overtime hours could mean the factory workers were at their job for 14 to 16 hours, with only meal breaks. Overtime hours were not always entirely voluntary: one woman related that she was occasionally forced by her employer to work on Sundays if a clothes' order was due. Most garment workers could earn a total of US\$60-70 per month with overtime. The women reported how the income made a difference in their lives, and the lives of their extended families:

Now I have enough money to survive and support family because after my mother died, my father took a second wife. My brother and sister live on their own. Now I have to support my brother and sister. (Migrant Woman 2, single, age 25, migrated 5 years ago)

Because the migrant women routinely sent a large portion of their income home to their families, several still found it difficult to manage on their remaining resources. The single migrant women usually reserved up to half of their monthly income for family support although this was not without challenges:

I send 50\% of my salary to my mother and I keep the rest for household expenses: electricity, water, and also for eating. The money is not enough. Sometimes I cannot send $50 \%$ of the money I make to my mother. (Migrant Woman 7, single, age 22, migrated 4 years ago)

Financial pressures meant that in many cases, women reported that they did not eat well; in their commitment to family well-being they compromised their own nutrition. The poor dietary standard of the migrant workers was confirmed by the following migrant, who struggled to cook on a very limited budget: 
My salary is $\$ 45$, with overtime I can get $\$ 50$ to $\$ 60$ per month. With the money that I have, I try to be very economical. If I am not economical, there will be insufficient money. For one day I have spent around 3,000 riel [US \$0.75] for food. I cook soup in the morning to keep for lunch and dinner. (Migrant woman 12, recently married, age 23 , migrated 5 years ago)

Many women would like to have had extra jobs outside the factory to supplement their income, but either could not find positions they were qualified for given their limited education, or had no energy or time after their long working days in the factory to pursue additional employment. The participants were asked if they were aware of any colleagues who worked in the "entertainment industry" as a means of further income generation. Although most women denied this, however, one observant migrant commented: "Some women at the garment factory also work as beer girls as the money is not sufficient." (Migrant woman 11, married, age 26, migrated 6 years ago)

"Beer girls" promote different brands of beer and are known as indirect sex workers (i.e. sometimes providing sexual services to men they meet in the course of their work). While only two of the migrants were aware of garment factory workers being employed in the entertainment industry, several of the women reported that they knew garment factory workers who had boyfriends in Phnom Penh. The migrant woman quoted below expressed her concern for this practice as she was aware this put her friends at risk:

One thing that I would like to say to you is that I am not happy to see the girls of the same age as me. I am not happy to see these girls getting boyfriends and sleeping with their boyfriends, and getting disease. I would prefer to see them get engaged. The way they carry on is not good. (Migrant woman 9, single, age 24, migrated 6 years ago)

While the interviewed women denied any involvement in sex work personally, several of the women were aware that they were at risk of HIV from the sexual indiscretions of their marriage partner. When asked if she may be at risk of HIV, one migrant admitted: "Actually I do not have 
experience about that, but I think the easiest way for me to get HIV/AIDS is through sex with my husband" (Migrant woman 14, married, age 26, migrated 5 years ago). This woman was clearly aware that her husband was her greatest source of vulnerability to HIV, due to his sexual liaisons with other women.

Access to health care was another issue that concerned the research participants. It was difficult for them to get time off from their factory line positions when needed, even for health appointments. Typically, they were allowed only one hour for visiting a clinic, which was impractical as they had to travel to the clinic and wait in line before being seen (fixed appointment times are not the norm in Cambodian public health facilities). When expressing their preferences for obtaining health care, the timeliness of the services was key, as was the friendliness of the service providers. At the time of the interviews, the public health care system was only available to the women during weekdays, although weekend clinics have since been arranged to accommodate the garment factory workers.

The private clinics are very polite. They are better, you get quick treatment. They pay more attention. RHAC [Reproductive Health Association of Cambodia, an NGO clinic] is polite and you get good care. I usually go to the private system as the public health care system is closed on Saturday and Sunday when I have time to go. The public health care system takes too long. I prefer to go to the private clinic, it is more time convenient. (Migrant Woman 2, single, age 25, migrated 5 years ago)

The factories also provide limited clinical services for the workers, however, these are designed for treatment of minor health problems such as headaches. The migrant workers generally did not seek care for reproductive health problems in these clinics. Their access to the factory clinics was tightly controlled by factory management, and several women commented that the quality of service at the factory clinics was inconsistent. The migrant worker cited below used the factory clinics for her health problems, though she was not happy about the limitations to access, the attitude of the health care worker, and the availability of medication: 
Yes, I went also to the factory clinic to take some medicine when I don't feel well or to do the coin massage [traditional medicine]. This is not good, because the health worker has a very nasty voice. Also the health workers have their own ground rules. In one month we are only allowed two visits for medicine. If you are sick more than this, then you cannot get medicine. They treat headache, cough and teeth pain, with the same medicine so I do not like to go. (Migrant Woman 16, widowed, age 28, migrated 3 years ago)

The other major complaint that some of the women had about their work in the factory was their limited exposure to health education programs. At the time of the interviews, several of the non-governmental organizations and the Ministry of Social Affairs were running health education programs for the garment factory workers in the factories. Only a limited number of women were selected to participate, and the smaller factories did not offer these programs at all. Those excluded from the education programs desired the opportunity to join their colleagues and learn more about their own health.

\section{Perspectives of the Key Informants and Health Care Providers}

Several of the issues expressed by the migrant garment factor workers were further elaborated by the key informants in interviews and health care providers in focus groups, and new issues were also raised. Almost all of the informants discussed poverty, lack of education, separation from the control and support of family, and peer pressure as contextual factors that contributed to vulnerability to HIV for the migrant garment factory workers. According to these informants, having left the protection and control of their families in the country-side, the young women were influenced by their peers and the media to develop relationships with local men. The key informants and health care providers described how the young men wooed the migrant women with gifts. Unfortunately, the men often terminated their relationships and moved on when their interest in the women lagged, leaving the women alone and vulnerable to further risky 
relationships or even sex work. According to a focus group participant, "When [a woman] has lost her virginity, she feels she does not have value, and then she may become an indirect sex worker." One key informant described how migrant women are enticed to have relationships with young men in Phnom Penh:

Girls have a lot of friends. Peers encourage them to enjoy the city life...Community factors [affecting HIV prevention] include the peer group, who the girls associate with. When she sees other women with boyfriends, she thinks why can't I have a boyfriend too, and get a lot of money and gifts. (Key informant, Government staff)

In addition, to consensual relationships, several of the focus group participants confirmed the migrant women's fears of street gangs. They reported their knowledge of several garment factory workers who had been raped after working late in the factories. Another risk that garment factory workers experienced is trafficking into the sex industry. A government official described the predicament this posed for some women:

As garment factory work is not seen as high status, sometimes sex workers are recruited by trafficking, and the girls are told they will have an office job. It is sad to say that once women are trapped into sex work, they can't escape: drop yourself in a big hole and you can never get out. Sex work is the end of her life. (Key Informant, Government staff)

The key informants and health care providers related that very few migrant garment factory workers took up extra jobs in the sex industry voluntarily. As one key informant described, the women did not have much time for sex work, with their very long hours in the factory. Improved pay in the factory jobs was another disincentive to sex work for these women.

In addition to sexual risks through consensual relationships and more rarely through exposure to sex work, the key informants expressed other concerns for the health of the garment factory workers. One key informant confirmed that in their efforts to send so much money home to their poor families, the migrant garment factory workers compromised their own health by living in substandard housing, and consuming an inadequate diet. 
Access to health care was also addressed by the key informants and health care providers. While there are more services available to the garment factory workers in the capital than in their villages, access remains an issue. Respondents confirmed that migrant women lack the knowledge of services, the financial resources to afford available services, and sometimes, the awareness that they have a health problem requiring medical care. The health care providers were very aware of the limitations on free time for these garment factory workers, and were frustrated as the women often were unable to return to the clinic to complete their treatment. While time restrictions limited access, the attitude of the health care provider was also an important issue. One key informant noted:

...for young women, young girls, if you go to the service for something like a sexually transmitted infection, maybe they don't get any respect from the service provider, they don't get good words from them. This is also a barrier for the women to go to the service as well. Some of them are saying that they don't want to go there because [the health care provider] might say something to them if they get a disease like that. So they just go to a traditional healer... Sometimes they just buy medicine from the pharmacy and just take it. (Key Informant, NGO staff)

The key informants also described how the lack of implementation of labour policies impacted on the migrant women's ability to prevent HIV infection, particularly overtime. While there is a Cambodian law prohibiting excess overtime, such laws are difficult to enforce. The key informants demonstrated concern that the workers were sometimes deprived of some basic human necessities such as access to health care when needed, clean water in the factories, and trained health care providers in the factory clinics.

\section{Discussion}

Despite stereotypes and common assumptions, it is neither migrants nor migration per se that increases the risks of HIV transmission. It is the trying conditions and hardships that many face throughout the migration experience that makes them more vulnerable to infection. (United Nations Population Fund, 2006, p. 16) 
The overarching theme arising from this research is the economic vulnerability of the migrant workers. Their poverty is the push factor for migration to the city. It limits their educational opportunities, and forces them to leave families behind and take on employment in the big city. Although the women make a reasonable income by Cambodian standards, their continued support of their families means that they remain functionally impoverished, and may thus have limited opportunities for good nutrition. Their limited economic resources may also encourage them to have relationships with local men (who buy them gifts) or occasionally to take on sex work as an income supplement.

The economic vulnerability of female migrants is a particularly important theme, for the poverty of women globally has been well established (Chen et al., 2005). Krishnan and colleagues have highlighted how poverty is a key driver of the global HIV epidemic in women (Krishnan et al., 2008). They argued that the negative consequences of migration make women especially vulnerable to HIV infection through limited educational opportunities, low-status and low paying jobs, and an increase in sex work. Such is the situation for Cambodian migrant garment factory workers: their educational opportunities have been limited by the need to provide for their families and they are thus forced to take on low status employment. While sex work was not a factor for the women we interviewed (or at least none of the women admitted to it), both the garment factory workers and the key informants knew of other workers who relied on this risky activity as an income supplement.

Two other themes are evident in the research: social vulnerability and occupational vulnerability, and these will be described in turn. When the migrant garment factory workers leave the support and control of their parents and their communities, they are left with a large void in their social support networks. While other migrant colleagues fill this gap, for some 
women their new-found friends may encourage them to pursue sexual relationships with local men according to the key informants. This social vulnerability is augmented by loneliness and absence of family restrictions. Migrants may breach the societal gender norms for acceptable behaviour for women that families reinforce (i.e. chastity until marriage), due to this social vulnerability. The society's gender norms may also prevent them from sharing information about their sexual relationships with the researchers, thus it is not unexpected that the key informants and health care providers were more vocal about the garment factory workers' sexual activities than the women themselves. The geographic move from the countryside to the city results in a social vulnerability for these migrant women that may contribute to their risk of acquiring HIV; however, they may not feel comfortable discussing this.

Social vulnerability for migrants to have casual sex has been documented for Chinese ruralto-urban migrants (Yang et al., 2007). These authors used quantitative measures and determined that lax social controls in the absence of family and community supports was the most significant mediating factor to explain migrants' increased HIV risk behaviours over their non-migrant colleagues. Research on young Nepalese migrant factory workers also noted that living in mixed gender hostels permitted more opportunities for sexual partnerships (Puri \& Cleland, 2006).

Occupational vulnerability, limiting health care access, is the third theme of this research. While factory employment is a life-changing experience for these women, providing them with the chance to help their rural families escape their desperate economic circumstances through respectable employment, there are also negative effects on their health status. Clearly, the factory management's primary motivation is production and profit; such factory pressures are transmitted to the workers. Access to health care services and health education programs are limited as the workers are not permitted time away from the production line. The pressure of 
production and profit may affect local factory policies - or adherence to policies - such as time off for healthcare appointments, over-time requirements, sick leave policies, and willingness to cooperate with government and non-governmental organization programmers to allow health education classes during working hours. Thus, factory pressures may limit migrant's knowledge of and access to HIV prevention services.

There are examples in the international literature on how factory work increases vulnerability to HIV for migrant workers. One quantitative study of Burmese migrant factory workers in Thailand noted their poor levels of knowledge about HIV, and attributed this in part to the lack of effective HIV prevention interventions for this population in their host country (Mullany, Maung, \& Beyrer, 2003). Studies of factory workers in northern Thailand (qualitative) (Theobald, 2002) and Nepal (quantitative) (Puri et al., 2006), have noted the increased vulnerability to HIV of migrant workers. but there was no critique or discussion of the factory policies that may have limited access to health care.

Work in the garment factories is also protective for many of these rural-to-urban migrant women. It provides these workers with a steady income and very little free time to explore personal or transactional sexual relationships. Without the opportunities that the garment factory work provides them, many more young rural Cambodian women would be forced to find employment in the brothels and entertainment establishments or as beer promoters, where the risks of acquiring HIV through sexual contact are much higher (Ministry of Health, 2006).

\section{Conclusion}

Coming of age for rural Cambodian women provides important employment opportunities in the city; work in the garment factories is one of the better options available to them. Obtaining a job producing clothes for people elsewhere in the world is the first step away from the poverty 
these women have been raised in. While this employment has benefits to the women and their families, their economic, social, and occupational vulnerabilities they experience in the city have significant impacts on the socio-ecologic context of HIV prevention for this population of women. More work now needs to be done to implement interventions for these migrants to help them gain knowledge and skills to engage in HIV prevention, and to modify some of the contextual factors in the community and the factory that have a negative impact on HIV prevention for these women. Based on the findings of this research, there are three areas where HIV prevention interventions for this population of women should be focused: expanded condom promotion, social supports for migrant workers, and factory policies and programs to protect workers.

The Cambodian government's 100\% condom policy has improved use of condoms amongst sex workers and their clients in brothel settings, but has had little effect on other sexual relationships (Wong et al, 2003). There is a need for further work promoting condom use for women who supplement their income with casual sex work (as is the case for some migrant garment factory workers) and for non-transactional sexual encounters with boyfriends and husbands. This is a key vulnerability for migrant women. Indeed, UNAIDS has raised the concern about the rising number of married Cambodian women who are contracting HIV, as almost half of all new infections are in this group (UNAIDS, 2008). Thus, there is an urgent need to prioritize the promotion of condom use beyond the brothels in Cambodia.

The migrant garment factory workers experience loneliness and isolation on arrival in the cities. These women are particularly socially vulnerable and interventions to help them adjust to the city may prevent them from making unsafe choices. For example, the factory could promote the development of peer orientation committees for new employees. These committees would 
provide social networks and support for migrant women. They could also introduce basic health education about HIV transmission and protection measures (such as abstinence and safe sex), in addition to information about local health care resources. Peer education and support would be an effective tool for addressing the social vulnerability of these workers.

Finally, monitoring the implementation of positive factory policies and programs to protect workers' access to health care and health education programming are examples of interventions that could enable young migrants to better protect themselves from the HIV epidemic spreading through Asia. Monitoring bodies such as the Cambodian government and the International Labour Organization should focus on ensuring that workers' rights to health are protected by enforcing overtime policies and assessing access to health care for workers. Factories could partner with non-governmental organizations to provide quality health care services that are both affordable and accessible to their employees. Such interventions would reduce the occupational vulnerability of migrant women to HIV.

There are several areas where additional research is called for. There is a need for additional research on both the positive and negative impacts of peers on migrants' vulnerability to HIV, for peer education is a key to the health education programs in Cambodian factories (CARE Cambodia, 2003). There is also a need for further research on the role of factory policies (and lack of implementation of policies) on the structural socio-ecologic context of HIV prevention. Research on the larger structural issues, including global trade policies, is also called for.

This research has demonstrated that the socio-ecologic framework is a valuable tool for understanding the context of HV vulnerability and prevention for migrant women. In addition to 
implementing the HIV prevention interventions discussed above, there is a need for further research to explore other aspects of the socio-ecologic context. In particular, research on the views of male partners and the impact of larger structural issues such as global trade policies and gender norms on HIV prevention for these migrant women will also prove helpful in understanding the context in which these women live and work, and could guide future interventions for this population.

\section{References}

Bandyopadhyay, M., \& Thomas, J. (2002). Women migrant workers' vulnerability to HIV infection in Hong Kong. AIDS Care, 14, 509-521.

Beyrer, Chris. (2007). HIV epidemiology update and transmission factors: risks and risk contexts--16th International AIDS Conference epidemiology plenary. Clinical Infectious Diseases, 44, 981-987.

Brewer, Toye H., Hasbun, Julia., Ryan, Caroline A., Hawes, Stephen E., Martinez, Samuel, Sanchez, Jorge, de Lister, Martha Butler, Constanzo, Jose, Lopez, Jose \& Holmes, King K. (1998). Migration, ethnicity and environment: HIV risk factors for women on the sugar cane plantations of the Dominican Republic. AIDS, 12, 1879-1887.

CARE Cambodia. (2003). A Stitch in Time Saves Nine: Tailoring Health in the Garment Factories: Evaluation and Comparison of a Sexual and Reproductive Health Project in Intervention and Non-Intervention Factories. Phnom Penh: CARE Cambodia.

CARE Cambodia. (2006). Cambodia: Women and Work in the Garment Industry. Phnom Penh: Care Cambodia. 
CARE International in Cambodia. (1999). Sewing a Better Future? A Report of Discussions with Young Garment Factory Workers about Life, Work and Sexual Health. Phnom Penh: Care Cambodia.

Chen, Martha, Vanek, Joann, Lund, Francie, Heintz, James, Jhabvala, Renana, \& Bonner, Christine. (2005). Progress of the World's Women 2005: Women, Work, and Poverty. New York: Unifem.

de Bruyn, M. (1992). Women and AIDS in developing countries. Social Science and Medicine, 34, 249-262.

Decosas, J., Kane, F., Anarfi, J. K., Sodji, D. K. R., \& Wagner, H. U. (1995). Migration and AIDS. The Lancet, 346, 826-828.

Derks, Annuska. (2008). Khmer Women on the Move: Exploring Work and Life in Urban Cambodia. Honolulu: University of Hawai'i Press.

Doyal, L. (1994). HIV and AIDS: Putting Women in the Global Agenda. In L. Doyal, J. Naidoo, and T. Wilton (eds.) AIDS: Setting a Feminist Agenda (pp. 11-29). London: Taylor and Francis.

Ebihara, May. (1974). Khmer Village Women in Cambodia: A Happy Balance. In Carolyn Matthiasson (ed.) Many Sisters: Women in Cross-Cultural Perspective (pp. 305-347). New York: Free Press.

Elam, Gillian, \& Fenton, Kevin A. (2003). Researching Sensitive Issues and Ethnicity: Lessons from Sexual Health. Ethnicity and Health, 8, 15-27. 
Fernandez, M. Isabel, Collazo, Jose B., Hernandez, Nilda, Bowen, G. Stephen, Varga, Leah M., Vila, Christie Kibort, Arheart, Christopher L., \& Perrino, Tatiana. (2004). Predictors of HIV Risk Among Hispanic Farm Workers in South Florida: Women Are at Higher Risk Than Men. AIDS \& Behavior, 8, 165-174.

Gadon, M., Chierici, R., \& Rios, P. (2001). Afro-American migrant farmworkers: a culture in isolation. AIDS Care, 13, 789-801.

Gilchrist, Valerie. (1992). Key Informant Interviews. In Benjamin Crabtree and William Miller (eds.) Doing Qualitative Research (pp. 70-89). Newbury Park: Sage.

Glaziou, Phillipe, Bodet, Charles, Loy, Thay, Vonthanak, Sophhann, El-Kouby, Sophie, \& Flye Sainte Marie, Francios. (1999). Knowledge, attitudes and practices of university students regarding HIV infection, in Phnom Penh, Cambodia, 1999. AIDS, 13, 1982-1983.

Gorbach, Pamina M., Sopheab, Heng, Chhorvann, Chhea, Weiss, Robert E., \& Vun, Mean Chhi. (2006). Changing behaviors and patterns among Cambodian sex workers: 19972003. Journal of Acquired Immune Deficiency Syndromes, 42, 242-247.

Gupta, G. \& Weiss, E. (1993). Women's lives and sex: implications for HIV prevention. Culture, Medicine \& Psychiatry, 17, 399-412.

Heise, L. \& Elias, C. (1995). Transforming AIDS Prevention to Meet Women's Needs: A Focus on Developing Countries. Social Science and Medicine, 40, 931-943. 
Hong, Yan, Stanton, Bonita, Li, Xiaoming, Yang, Hongmei, Lin, Danhua., Fang, Xiaoyi, Wang, Jing, \& Mao, Rong. (2006). Rural-to-urban migrants and the HIV epidemic in China. AIDS and Behavior, 10, 421-430.

Hu, Z., Liu, H., Li, X., Stanton, B., \& Chen, X. (2006). HIV-related sexual behaviour among migrants and non-migrants in a rural area of China: Role of rural-to-urban migration. Public Health, 120, 339-345.

International Labour Organization. (2005). Better Factories Cambodia: Facts and Figures. Retrieved July 10, 2007 from http://www.betterfactories.org/content/documents/Facts\%20and\%20Figures.pdf

Kim, Andrea A., Sun, Ly Penh, Chhorvann, Chhea, Lindan, Christina, Van Griensven, Frits, Kilmarx, Peter H., Sirivongrangson, Pachara, Louie, Janice K., Leng, Hor Bun, \& PageSchafer, Kimberly. (2005). High prevalence of HIV and sexually transmitted infections among indirect sex workers in Cambodia. Sexually Transmitted Diseases, 32, 745-751.

Krishnan, Suneeta, Dunbar, Megan S., Minnis, Alexandra M., Medlin, Carol, A., Gerdts, Caitlin, E., \& Padian, Nancy S. (2008). Poverty, Gender Inequities and Women's risk of HIV/AIDS. Annals of the New York Academy of Sciences, 1136, 101-110.

Ledgerwood, Judy. (1990). Changing Khmer Conceptions of Gender: Women, Stories and the Social Order. Ph.D. dissertation, Cornell University.

MacPherson, Douglas W., Gushulak, Brian. D., \& Macdonald, Liane. (2007). Health and foreign policy: influences of migration and population mobility. Bulletin of the World Health Organization, 85, 200-206. 
Maltoni, Bruno. (2006). Review of Labor Migration Dynamics in Cambodia. Phnom Penh: International Organization for Migration.

Mills, Edward, Singh, Sonal, Orbinski, James, \& Burrows, Dave. (2005). The HIV/AIDS epidemic in Cambodia. The Lancet Infectious Diseases, 5, 596-597.

Ministry of Health. (2006). Report on HIV Sentinel Surveillance in Cambodia 2003. Phnom Penh: Ministry of Health - National Center for HIV/AIDS, Dermatology and STDs.

Mullany, L. C., Maung, C., \& Beyrer, C. (2003). HIV/AIDS knowledge, attitudes, and practices among Burmese migrant factory workers in Tak Province, Thailand. AIDS Care, 15, 63-70.

Nareoun, T. (2004). The economic impact of garment factory workers on their own families in the village. In Rural Urban Migration in Cambodia (pp. 77-120). Phnom Penh: Royal University of Phnom Penh.

National Center for HIV/AIDS Dermatology and STDs \& University of California, L. A. (2005). Sexual Risk and HIV/STD in Vulnerable Cambodian Females, The Cambodian Young Women's Cohort: Factory Workers Phnom Penh: National Center for HIV/AIDS Dermatology and STDs.

Nishigaya, Kasumi. (2002). Female garment factory workers in Cambodia: migration, sex work and HIV/AIDS. Women and Health, 35, 27-42.

Ohshige, K., Morio, S., Mizushima, S., Kitamura, K., Tajima, K., Ito, A., Suyama, A., Usuku, S., Saphonn, V., Heng, S., Hor, L.B., Tia, P., \& Soda, K. (2000a). Cross-sectional study 
on risk factors of HIV among female commercial sex workers in Cambodia. Epidemiology and Infection, 124, 143-152.

Ohshige, K., Morio, S., Mizushima, S., Kitamura, K., Tajima, K., Suyama, A., Usuku, S., Tia, P. Hor, L.B., Heng, S., Saphonn, V., Tochikubo, O. \& Soda, K. (2000b). Behavioural and serological human immunodeficiency virus risk factors among female commercial sex workers in Cambodia. International Journal of Epidemiology, 29, 344-354.

Parker, R. \& Aggleton, P. (2007). Culture, Society and Sexuality: A Reader ( $2^{\text {nd }}$ Edition). New York: Routledge.

Prybylski, D. \& Alto, W. A. (1999). Knowledge, attitudes and practices concerning HIV/AIDS among sex workers in Phnom Penh, Cambodia. AIDS Care, 11, 459-472.

Puri, M. \& Cleland, J. (2006). Sexual behavior and perceived risk of HIV/AIDS among young migrant factory workers in Nepal. Journal of Adolescent Health, 38, 237-246.

Quinn, Thomas C. (1994). Population migration and the spread of types 1 and 2 human immundeficiency viruses. Proceedings of the National Academy of Sciences of the United States of America, 91, 2407-2414.

Rhodes, Tim. \& Simic, Milena. (2005). Transition and the HIV risk environment. British Medical Journal, 331, 220-223.

Sandy, Larissa (2006). Sex work in Cambodia: Beyond the voluntary/forced dichotomy. Asian and Pacific Migration Journal, 15, 449-469. 
Saphonn, Vonthanak, Sopheap, Heng, Sun, Ly Penh, Vun, Mean Chhi, Wantha, Seng Suth, Gorbach, Pamina M. \& Detels, Roger. (2004). Current HIV/AIDS/STI epidemic: intervention programs in Cambodia, 1993-2003. AIDS Education and Prevention, 16 (3 Suppl A), 64-77.

Schoepf, Brooke G. (1992). Gender Relations and Development: Political Economy and Culture. In Ann Seidman and Frederick Anang (eds.) Twenty-First-Century Africa: Towards a New Vision of Self-Sustainable Development. Trenton: Africa World Press.

Stone, Valerie, Catania, Joseph, \& Binson, Diane. (1999). Measuring Change in Sexual Behaviour: Concordance Between Survey Measures. The Journal of Sex Research, 36, 102-108.

Tarr, Chou Meng, \& Aggleton, P. (1999). Young people and HIV in Cambodia: Meanings, contexts and sexual cultures. AIDS Care, 11, 375-384.

Temple, Bogusia. (2002). Crossed wires: interpreters, translators, and bilingual workers in cross-language research. Qualitative Health Research, 12, 844-854.

Theobald, Sally. (2002). Gendered bodies: Recruitment, management and occupational health in northern Thailand's electronics factories. Women and Health, 35, 7-26.

UNAIDS. (2007a). 07 AIDS epidemic update. Retrieved December 30, 2007 from http://data.unaids.org/pub/EPISlides/2007/2007_epiupdate_en.pdf

UNAIDS. (2007b). Uniting the world against AIDS: Cambodia. Retrieved October 27, 2007, from http://www.unaids.org/en/Regions_Countries/Countries/cambodia.asp 
UNAIDS. (2008). Cambodia Country Situation July 2008. Retrieved May 1, 2009 from http://data.unaids.org/pub/FactSheet/2008/sa08_cam_en.pdf

United Nations Development Program. (2007). UNDP - Cambodia. Retrieved October 12,2007 , from http://www.un.org.kh/undp/content/index.php?option=com_content\&task=blogcategoryEn\&id= $\underline{6 \& \text { Itemid }=45}$

United Nations Population Fund. (2006). A passage of hope: Women and international migration. Retrieved October 15, 2007 from http://www.unfpa.org/upload/lib_pub_file/650_filename_sowp06-en.pdf

Webber, Gail. (2007). The impact of migration on HIV prevention for women: Constructing a conceptual framework. Health Care for Women International, 28, 712-730.

Webber, Gail. (2008). Life in the Big City: Understanding the Context of HIV Prevention for Rural-to-Urban Migrant Cambodian Garment Factory Workers. University of Ottawa Doctoral Thesis.

Wiederman, Michael (2002). Reliability and Validity of Measurement. In Michael Wiederman and Bernard Whitley (eds). Handbook for Conducting Research on Human Sexuality (pp. 25-50). Mahwah: Lawrence Erlbaum Associates

Wong, M. L., Lubek, I., Dy, B. C., Pen, S., Kros, S., \& Chhit, M. (2003). Social and behavioural factors associated with condom use among direct sex workers in Siem Reap, Cambodia. Sexually Transmitted Infections, 79, 163-165. 
Yang, X., Derlega, V. J., \& Luo, H. (2007). Migration, behaviour change and HIV/STD risks in China. AIDS Care, 19, 282-288.

Yang, Xiushi, \& Xia, Guomei. (2006). Gender, migration, risky sex, and HIV infection in China. Studies in Family Planning, 37, 241-249.

Zierler, S. \& Krieger, N. (1997). Reframing Women’s Risk: Social Inequalities and HIV Infection. Annual Review of Public Health, 18, 401-436. 
Figure 1

(From Webber, Gail (2007). The impact of migration on HIV prevention for women: Constructing a conceptual framework. Health Care for Women International, 28, 725.

Reprinted with permission of Taylor and Francis. Journal website: www.informaworld.com)

\section{CONCEPTUAL FRAMEWORK OF THE IMPACT OF MIGRATION ON HIV PREVENTION FOR WOMEN}

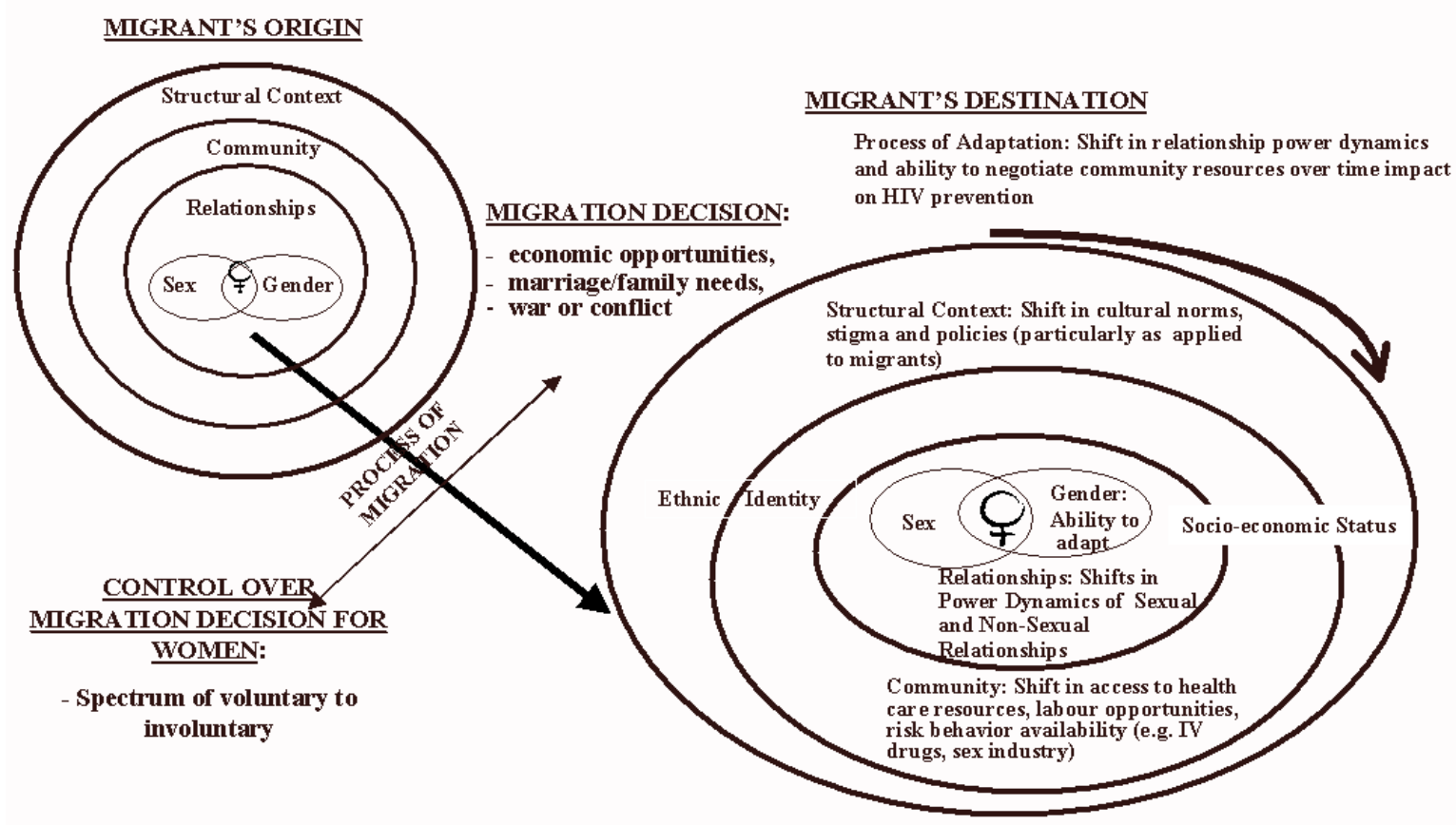

